2016

\title{
Optimum Gear Ratios for an Electric Vehicle
}

Scott Parkinson

University of South Florida

\author{
Advisors: \\ Kanaka Nallamshetty, Mathematics and Statistics \\ Jonathan Burns, Mathematics and Statistics \\ Scott Campbell, Chemical and Biomedical Engineering \\ Problem Suggested By: Scott Campbell
}

Follow this and additional works at: https://digitalcommons.usf.edu/ujmm

Part of the Mathematics Commons

UJMM is an open access journal, free to authors and readers, and relies on your support:

Donate Now

\section{Recommended Citation}

Parkinson, Scott (2016) "Optimum Gear Ratios for an Electric Vehicle," Undergraduate Journal of Mathematical Modeling: One + Two: Vol. 7: Iss. 1, Article 4.

DOI: http://dx.doi.org/10.5038/2326-3652.7.1.4875

Available at: https://digitalcommons.usf.edu/ujmm/vol7/iss1/4 


\title{
Optimum Gear Ratios for an Electric Vehicle
}

\begin{abstract}
The goal of this project is to determine the optimal gear ratios for a vehicle containing a four-speed transmission. This vehicle is required to reach a speed of $30 \mathrm{~m} / \mathrm{s}$ in the minimum time possible. Equations for the velocity at each shift point were found. An equation for the total time that the vehicle took to reach $30 \mathrm{~m} / \mathrm{s}$ was then derived and equations for the times spent in each gear were found through integration of the provided formula for acceleration. The optimal gear ratios were then found by taking the partial derivatives of the total time equation with respect to each gear ratio. These equations were set equal to zero and solved by the method of substitution to obtain the optimum value for each gear ratio. These results would provide engineers with the information required to efficiently develop transmissions to reach particular speeds in a minimum amount of time.
\end{abstract}

\section{Keywords}

transmission, gear ratios, optimization

\section{Creative Commons License}

(c) (i) $\ominus$

This work is licensed under a Creative Commons Attribution-Noncommercial-Share Alike 4.0 License. 


\section{PROBLEM STATEMENT}

A vehicle powered by an electric motor has a mass $M$ (car + driver) of $600 \mathrm{~kg}$ and a wheel radius of $0.25 \mathrm{~m}$. It is to have a four-speed transmission and the goal of this project is to find the optimal gear ratios $\mathrm{GR}_{1}, \mathrm{GR}_{2}, \mathrm{GR}_{3}$ and $\mathrm{GR}_{4}$ for the transmission.

A graph of engine torque versus engine (angular) speed is shown below for the electric motor. Note that the engine can maintain a nearly constant torque until the rotational speed reaches a certain value, at which point the torque produced begins to fall off. A reasonable approach to shifting is to shift to the next gear just before the torque begins to fall off. We will assume here that the engine can maintain a torque of $240 \mathrm{~N} \cdot \mathrm{m}$ to a speed of $2500 \mathrm{RPM}$ and that the driver will shift to the next gear at 2500 RPM.

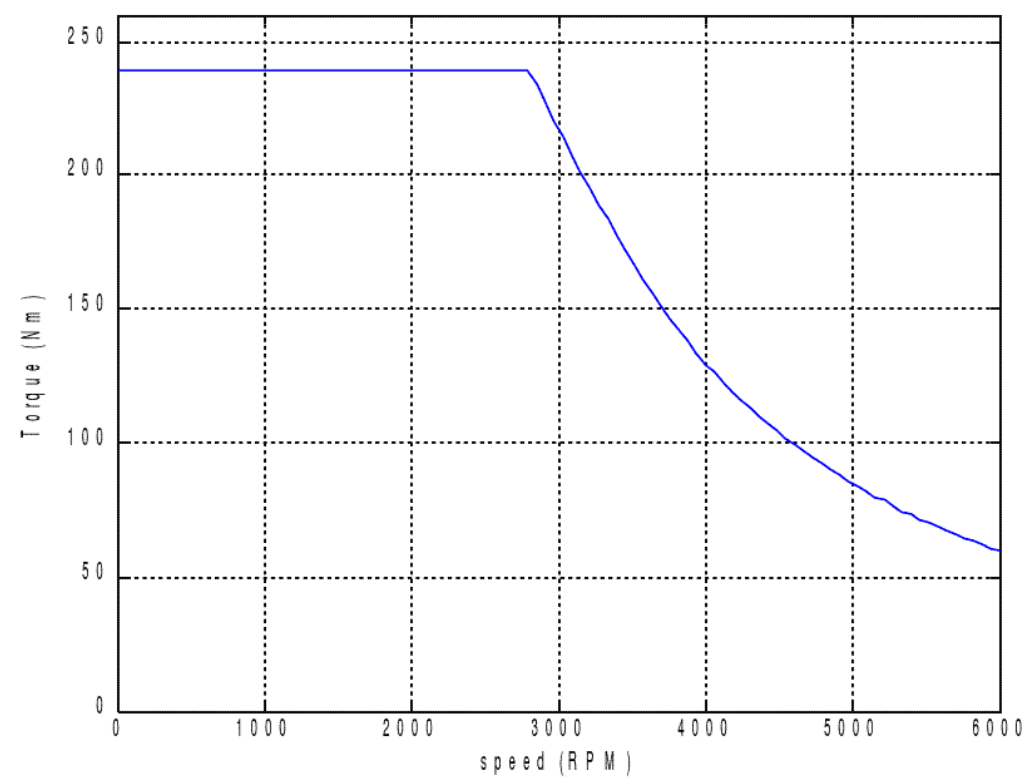

The equations for the velocity $\mathrm{v}$ and acceleration $\mathrm{dv} / \mathrm{dt}$ of the vehicle are:

$$
v=\frac{R \omega_{E}}{\left(G R_{i}\right) \cdot F D R} \quad \text { and } \quad \frac{d v}{d t}=\frac{\tau \cdot F D R \cdot G R_{i}}{M \cdot R}
$$


where $\omega_{\mathrm{E}}$ is the engine speed in radians/s, and $\tau$ is the engine torque produced. $\mathrm{M}$ and $\mathrm{R}$ are the vehicle mass and wheel radius and GR is the gear ratio. Its value depends on what gear $(\mathrm{i}=1,2$, 3 or 4 ) the transmission is in. FDR is the final drive ratio, which will be 3.0.

(a) One goal of the design is for the vehicle to reach a velocity of $30 \mathrm{~m} / \mathrm{s}$ when the engine is turning 2500 RPM in 4th gear. Use this criterion to calculate GR4.

(b) Another goal of the design is that the vehicle reaches the speed of $30 \mathrm{~m} / \mathrm{s}$ in the minimum total time. Find the gear ratios $\mathrm{GR}_{1}, \mathrm{GR}_{2}$ and $\mathrm{GR}_{3}$ that will minimize the total time needed to reach a velocity of $30 \mathrm{~m} / \mathrm{s}$. You may assume that the vehicle starts from rest and that the velocity $\mathrm{v}$ of the vehicle is continuous at the shift points.

(c) In addition to finding the optimum gear ratios, calculate the corresponding total time needed to reach $30 \mathrm{~m} / \mathrm{s}$, the times $\mathrm{t}_{1}, \mathrm{t}_{2}, \mathrm{t}_{3}$ and $\mathrm{t}_{4}$ that the vehicle spends in each gear, and the velocities $\mathrm{v}_{1}, \mathrm{v}_{2}$, and $\mathrm{v}_{3}$ at the shift points from first to second gear, from second to third gear, and from third to fourth gear.

\section{MOTIVATION}

This problem is important to engineering in that the engineers will already be provided with the information that they might need to make calculations towards achieving a goal of designing a vehicle's transmission to reach a particular speed as quickly as possible. This would more specifically appeal to racing development firms because they would be focusing on achieving the optimum gear ratios that would help improve the performance of their racing vehicle. The motor used to power this vehicle is electric. The results provided would therefore only be of major significance if the same type of motor was being used in another project. However, even if an electric motor was not being used, the information could still be used for readers to receive a greater understanding of how the gear ratios should generally be determined. 
The objective of this project is to find the optimal gear ratios for each gear of a four-speed transmission that will minimize the total time required for the vehicle to reach a speed of $30 \mathrm{~m} / \mathrm{s}$.

\section{MATHEMATICAL DESCRIPTION AND SOLUTION APPROACH}

We use

$$
\text { Equation 1: Velocity }(v)=\frac{R \omega_{E}}{\left(G R_{i}\right) \cdot F D R}
$$

and

$$
\text { Equation 2: Acceleration }\left(\frac{d v}{d t}\right)=\frac{\tau \cdot F R D \cdot\left(G R_{i}\right)}{M \cdot R} \text {, }
$$

where

$M($ mass of car + driver $)=600 \mathrm{~kg}$

$R($ wheel radius $)=0.25 \mathrm{~m}$,

$\tau($ torque $)=240 \mathrm{Nm}$

$\omega_{E}($ engine speed $)=2500 R P M \times \frac{1}{2 \pi} \times 60 \mathrm{~s}=261.799 \mathrm{rad} / \mathrm{s}$,

$F D R($ final drive ratio $)=3.0$,

$G R_{i}($ gear ratio $) ;(i=1,2,3$ or 4$)$.

(a) The value of $\mathrm{GR}_{4}$ is calculated using the equation for velocity provided: $=\frac{R \omega_{E}}{\left(G R_{4}\right) \cdot F D R}$,

hence

$\therefore G R_{4}=0.727 \mathrm{rad}$.

(b) Equations for the velocities $v_{i} ;(i=0,1,2,3,4)$ at each of the shift points can be determined

using the equation for velocity provided. The value of $v_{0}$ is $0 \mathrm{~m} / \mathrm{s}$ because it is the initial velocity

before the vehicle started moving. The value of $v_{1}$ can be considered to be the velocity of the

vehicle at the shift point from $1^{\text {st }}$ to $2^{\text {nd }}$ gear. The values of $v_{2}$ and $v_{3}$ will obviously be

considered to be the velocity at the shift points from $2^{\text {nd }}$ to $3^{\text {rd }}$ gear and $3^{\text {rd }}$ to $4^{\text {th }}$ gear 
respectively. The value of $v_{4}$ as we know already is the final velocity of $30 \mathrm{~m} / \mathrm{s}$. The gear ratios must correspond to their respective shift point velocities. For example: $G R_{1}$ and $v_{1}$ etc.

$v_{i}=\frac{R \omega_{E}}{\left(G R_{i}\right) \cdot F D R}$

The formula provided for acceleration can be integrated in order to obtain an equation for velocity in terms of $t_{i} ;(i=1,2,3,4)$, where $t_{i}$ is the time spent in a particular gear:

$$
\begin{gathered}
\int_{v_{i}}^{v_{i}} d v_{i}=\frac{\tau \cdot F D R \cdot\left(G R_{i}\right)}{M \cdot R} \int_{0}^{t_{i}} d t, \\
v_{i}-v_{i}=\frac{\tau \cdot F D R \cdot\left(G R_{i}\right)}{M \cdot R}\left(t_{i}\right) .
\end{gathered}
$$

Substituting the equations for $v$ from above results in:

$$
\frac{R \omega_{E}}{\left(G R_{i}\right) \cdot F D R}-\frac{R \omega_{E}}{\left(G R_{i}\right) \cdot F D R}=\frac{\tau \cdot F D R \cdot\left(G R_{i}\right)}{M \cdot R}\left(t_{i}\right)
$$

Solving for $t_{i}$ :

$t_{i}=\frac{R^{2} \omega_{E} M}{\tau \cdot F D R^{2}} \cdot\left(\frac{1}{\left(G R_{i}\right)^{2}}-\frac{1}{\left(G R_{i}\right)\left(G R_{i}\right)}\right)$

An equation for the total minimum time required for the vehicle to reach a velocity of $30 \mathrm{~m} / \mathrm{s}$ is:

$$
t_{t}=t_{1}+t_{2}+t_{3}+t_{4}
$$

Substituting for the equations for $t_{i}$ from above results in:

$$
\begin{aligned}
t_{t}=\frac{R^{2} \omega_{E} M}{\tau \cdot F D R^{2}} & {\left[\frac{1}{\left(G R_{1}\right)^{2}}+\frac{1}{\left(G R_{2}\right)^{2}}-\frac{1}{\left(G R_{1}\right)\left(G R_{2}\right)}+\frac{1}{\left(G R_{3}\right)^{2}}-\frac{1}{\left(G R_{2}\right)\left(G R_{3}\right)}+\frac{1}{\left(G R_{4}\right)^{2}}\right.} \\
& \left.-\frac{1}{\left(G R_{3}\right)\left(G R_{4}\right)}\right]
\end{aligned}
$$

Equations for the partial derivatives of the total minimum time with respect to each gear ratio are:

$$
\frac{\partial t_{t}}{\partial G R_{1}}=\frac{R^{2} \omega_{E} M}{\tau \cdot F D R^{2}}\left[-\frac{2}{\left(G R_{1}\right)^{3}}+\frac{1}{\left(G R_{1}\right)^{2}\left(G R_{2}\right)}\right] \text {, }
$$




$$
\begin{aligned}
\frac{\partial t_{t}}{\partial G R_{2}} & =\frac{R^{2} \omega_{E} M}{\tau \cdot F D R^{2}}\left[-\frac{2}{\left(G R_{2}\right)^{3}}+\frac{1}{\left(G R_{1}\right)\left(G R_{2}\right)^{2}}+\frac{1}{\left(G R_{2}\right)^{2}\left(G R_{3}\right)}\right], \\
\frac{\partial t_{t}}{\partial G R_{3}} & =\frac{R^{2} \omega_{E} M}{\tau \cdot F D R^{2}}\left[-\frac{2}{\left(G R_{3}\right)^{3}}+\frac{1}{\left(G R_{2}\right)\left(G R_{3}\right)^{2}}+\frac{1}{\left(G R_{3}\right)^{2}\left(G R_{4}\right)}\right] .
\end{aligned}
$$

Set each equation $[(1),(2),(3)]=0$ and solving by method of substitution results in equations for the optimum gear ratios:

$$
G R_{1}=2\left(G R_{2}\right) ; G R_{2}=2 G R_{4} ; G R_{3}=\frac{2}{3}\left(G R_{2}\right)
$$

Substituting for the value of $G R_{4}$ calculated in part (a) you can calculate the values of the optimum gear ratios:

$$
G R_{1}=2.908 \mathrm{rad} ; G R_{2}=1.454 \mathrm{rad} ; G R_{3}=0.969 \mathrm{rad}
$$

(c) The values that were found for each gear ratio can be substituted into the equations that were derived for the velocities at the shift points $\left(v_{i}\right)$, the times that the vehicle spends in each gear $t_{i}$ and the total time needed to reach a velocity of $30 \mathrm{~m} / \mathrm{s}\left(t_{t}\right)$ to calculate these corresponding values.

$$
\begin{gathered}
v_{1}=7.502 \mathrm{~m} / \mathrm{s} ; v_{2}=15.00 \mathrm{~m} / \mathrm{s} ; v_{3}=22.51 \mathrm{~m} / \mathrm{s} \\
t_{1}=0.537 \mathrm{~s} ; t_{2}=1.075 \mathrm{~s} ; t_{3}=1.615 \mathrm{~s} ; t_{4}=2.148 \mathrm{~s} \\
t_{t}=5.375 \mathrm{~s}
\end{gathered}
$$

\section{DISCUSSION}

The gear ratios decreased for each gear from $1^{\text {st }}$ to $4^{\text {th }}$. This result was as expected because the gear ratios typically decrease in this order. It was observed however, that the gear ratio for $1^{\text {st }}$ gear was by far the longest when comparing the differences between the other gear ratios. The gear ratios $\left(\mathrm{GR}_{2}, \mathrm{GR}_{3}\right.$ and $\left.\mathrm{GR}_{4}\right)$ could be considered to be close-ratio because of a smaller progression between the gears. This wide-ratio between $1^{\text {st }}$ gear and $2^{\text {nd }}$ gear is due to the 
vehicle needing to spend more time in $1^{\text {st }}$ gear because it was starting from rest with a low engine speed. At the shift points between the other gears, the engine speed would not drop by such a great amount and thus the other gear ratios were shorter because less time was required to reach an engine speed of 2500 RPM. As each gear is shifted at 2500 RPM, the time required for the following gear to reach that same engine speed is shorter because at each progressing shift point, the engine speed does not drop by as much as the one before it since the velocity of the vehicle is increasing.

These results provide accurate information as to how you can calculate the optimal gear ratios for a vehicle to reach a particular speed. Engineers can readily draw on these results to save them time in making accurate calculations. These would help in the field in general by providing a useful template when making similar calculations without the engineers having to spend time trying to solve such a problem.

\section{CONCLUSIONS AND RECOMMENDATIONS}

From the information gathered in this project, the results can be used to aid in the improvement of transmissions to reach particular speeds in a minimum total time. It was observed that the optimum gear ratios needed for this to occur should have relatively small progressions up until each shift point, with these progressions decreasing between each gear as the velocity of the vehicle increases. For example: GR 1 should have the longest progression before changing to $2^{\text {nd }}$ gear and $\mathrm{GR}_{3}$ should have the shortest progression before changing to $4^{\text {th }}$ gear. For others working on a similar type of project, it must be noted that this problem is based on a vehicle that is being powered by an electric motor. Therefore, unless the vehicle in their project is also being powered by the same type of motor, these results would prove invalid. This is because the torque would not be constant at all engine speeds up until 2500 RPM as is the case 
for this particular electric motor. An example of a different type of motor could be an internal combustion engine.

\section{NOMENCLATURE}

\begin{tabular}{|c|c|c|}
\hline V & Velocity & $\mathrm{m} / \mathrm{s}$ \\
\hline $\mathrm{T}$ & Time & $\mathrm{s}$ \\
\hline $\mathrm{GR}_{\mathrm{i}}$ & Gear Ratio & $\mathrm{rad}$ \\
\hline $\mathrm{R}$ & Wheel Radius & $\mathrm{kg}$ \\
\hline $\mathrm{M}$ & Mass (car + driver) & $\mathrm{RPM}$ \\
\hline$\omega_{\mathrm{e}}$ & Engine Speed & $\mathrm{Nm}$ \\
\hline$\tau$ & Torque & - \\
\hline FDR & Final Drive Ratio & \\
\hline
\end{tabular}

\section{REFERENCES}

Kempton, Willett, and Steven E. Letendre. "Electric vehicles as a new power source for electric utilities." Transportation Research Part D: Transport and Environment 2 (1997): 157-175. Tsukamoto, Kazumasa, Masao Kawai, and Hideki Aruga. Vehicle transmission controller for changing gear ratios in accordance with road features. USA: Patent 6,098,005. 1 August 2000. Van Der Woude, Luc HV, et al. "Handcycling: different modes and gear ratios." Journal of medical engineering \& technology (2000): 242-249.

"Transmission Gear Ratios - TCI® Auto." High Performance Automatic Transmissions \& Parts - TCI® Auto. N.p., n.d. Web. 20 Apr. 2014. 


\section{APPENDIX}

(a)

From Equation 1:

$$
\begin{gathered}
v=\frac{R \omega_{E}}{\left(G R_{4}\right) \cdot F D R} \\
\therefore G R_{4}=\frac{R \omega_{E}}{v \cdot F D R}=\frac{(0.25 \mathrm{~m})(261.799 \mathrm{rad} / \mathrm{s})}{(30 \mathrm{~m} / \mathrm{s})(3.0)}=0.727 \mathrm{rad}
\end{gathered}
$$

(b)

$$
v_{0}=0 \mathrm{~m} / \mathrm{s} ; \text { Where } v_{0} \text { is the initial velocity. }
$$

From equation 1:

$$
\begin{gathered}
v_{1}=\frac{R \omega_{E}}{\left(G R_{1}\right) \cdot F D R} ; \text { Where } v_{1} \text { is the velocity at the shift point from } 1^{\text {st }} \text { to } 2^{\text {nd }} \text { gear. } \\
v_{2}=\frac{R \omega_{E}}{\left(G R_{2}\right) \cdot F D R} ; \text { Where } v_{2} \text { is the velocity at the shift point from } 2^{\text {nd }} \text { to } 3^{\text {rd }} \text { gear. } \\
v_{3}=\frac{R \omega_{E}}{\left(G R_{3}\right) \cdot F D R} ; \text { Where } v_{3} \text { is the velocity at the shift point from } 3^{r d} \text { to } 4^{\text {th }} \text { gear. } \\
v_{4}=\frac{R \omega_{E}}{\left(G R_{4}\right) \cdot F D R} ; \text { Where } v_{4} \text { is the final velocity }(30 \mathrm{~m} / \mathrm{s}) \text { in } 4^{\text {th }} \text { gear. }
\end{gathered}
$$

From equation 2:

$$
\begin{gathered}
\frac{d v_{1}}{d t_{1}}=\frac{\tau \cdot F R D \cdot\left(G R_{1}\right)}{M \cdot R} \\
\int_{v_{0}}^{v_{1}} d v_{1}=\frac{\tau \cdot F D R \cdot\left(G R_{1}\right)}{M \cdot R} \int_{0}^{t_{1}} d t \\
v_{1}-v_{0}=\frac{\tau \cdot F D R \cdot\left(G R_{1}\right)}{M \cdot R}\left(t_{1}\right)
\end{gathered}
$$




$$
v_{1}=\frac{\tau \cdot F D R \cdot\left(G R_{1}\right)}{M \cdot R}\left(t_{1}\right)
$$

Substituting for $v_{1}$ from above: $\frac{R \omega_{E}}{\left(G R_{1}\right) \cdot F D R}=\frac{\tau \cdot F D R \cdot\left(G R_{1}\right)}{M \cdot R}\left(t_{1}\right)$

$$
\therefore t_{1}=\frac{R^{2} \omega_{E} M}{\tau \cdot F D R^{2}} \cdot \frac{1}{\left(G R_{1}\right)^{2}} ; \text { Where } t_{1} \text { is the time spent in } 1^{\text {st }} \text { gear. }
$$

From equation 2:

$$
\begin{gathered}
\frac{d v_{2}}{d t_{2}}=\frac{\tau \cdot F R D \cdot\left(G R_{2}\right)}{M \cdot R} \\
\int_{v_{1}}^{v_{2}} d v_{2}=\frac{\tau \cdot F D R \cdot\left(G R_{2}\right)}{M \cdot R} \int_{0}^{t_{2}} d t \\
v_{2}-v_{1}=\frac{\tau \cdot F D R \cdot\left(G R_{2}\right)}{M \cdot R}\left(t_{2}\right)
\end{gathered}
$$

Substitute for $v_{1}$ and $v_{2}$ from above: $\frac{R \omega_{E}}{\left(G R_{2}\right) \cdot F D R}-\frac{R \omega_{E}}{\left(G R_{1}\right) \cdot F D R}=\frac{\tau \cdot F D R \cdot\left(G R_{2}\right)}{M \cdot R}\left(t_{2}\right)$

$$
\therefore t_{2}=\frac{R^{2} \omega_{E} M}{\tau \cdot F D R^{2}} \cdot\left(\frac{1}{\left(G R_{2}\right)^{2}}-\frac{1}{\left(G R_{1}\right)\left(G R_{2}\right)}\right) ; \text { Where } t_{2} \text { is the time spent in } 2^{\text {nd }} \text { gear. }
$$

From equation 2:

$$
\begin{gathered}
\frac{d v_{3}}{d t_{3}}=\frac{\tau \cdot F R D \cdot\left(G R_{3}\right)}{M \cdot R} \\
\int_{v_{2}}^{v_{3}} d v_{2}=\frac{\tau \cdot F D R \cdot\left(G R_{3}\right)}{M \cdot R} \int_{0}^{t_{3}} d t \\
v_{3}-v_{2}=\frac{\tau \cdot F D R \cdot\left(G R_{3}\right)}{M \cdot R}\left(t_{3}\right)
\end{gathered}
$$


Substitute for $v_{2}$ and $v_{3}$ from above: $\frac{R \omega_{E}}{\left(G R_{3}\right) \cdot F D R}-\frac{R \omega_{E}}{\left(G R_{2}\right) \cdot F D R}=\frac{\tau \cdot F D R \cdot\left(G R_{3}\right)}{M \cdot R}\left(t_{3}\right)$

$$
\therefore t_{3}=\frac{R^{2} \omega_{E} M}{\tau \cdot F D R^{2}} \cdot\left(\frac{1}{\left(G R_{3}\right)^{2}}-\frac{1}{\left(G R_{2}\right)\left(G R_{3}\right)}\right) ; \text { Where } t_{3} \text { is the time spent in } 3^{\text {rd }} \text { gear. }
$$

From equation 2:

$$
\begin{aligned}
\frac{d v_{4}}{d t_{4}} & =\frac{\tau \cdot F R D \cdot\left(G R_{4}\right)}{M \cdot R} \\
\int_{v_{3}}^{v_{4}} d v_{2} & =\frac{\tau \cdot F D R \cdot\left(G R_{4}\right)}{M \cdot R} \int_{0}^{t_{4}} d t \\
v_{4}-v_{3} & =\frac{\tau \cdot F D R \cdot\left(G R_{4}\right)}{M \cdot R}\left(t_{4}\right)
\end{aligned}
$$

Substitute for $v_{3}$ and $v_{4}$ from above: $\frac{R \omega_{E}}{\left(G R_{4}\right) \cdot F D R}-\frac{R \omega_{E}}{\left(G R_{3}\right) \cdot F D R}=\frac{\tau \cdot F D R \cdot\left(G R_{4}\right)}{M \cdot R}\left(t_{4}\right)$

$$
\therefore t_{4}=\frac{R^{2} \omega_{E} M}{\tau \cdot F D R^{2}} \cdot\left(\frac{1}{\left(G R_{4}\right)^{2}}-\frac{1}{\left(G R_{3}\right)\left(G R_{4}\right)}\right) ; \text { Where } t_{4} \text { is the time spent in } 4^{\text {th }} \text { gear. }
$$

$t_{t}=t_{1}+t_{2}+t_{3}+t_{4} ;$ Where $t_{t}$ is the total time needed to reach $30 \mathrm{~m} / \mathrm{s}$.

$$
\begin{aligned}
t_{t}=\left[\frac{R^{2} \omega_{E} M}{\tau \cdot F D R^{2}} \cdot\right. & \left.\frac{1}{\left(G R_{1}\right)^{2}}\right]+\left[\frac{R^{2} \omega_{E} M}{\tau \cdot F D R^{2}} \cdot\left(\frac{1}{\left(G R_{2}\right)^{2}}-\frac{1}{\left(G R_{1}\right)\left(G R_{2}\right)}\right)\right] \\
& +\left[\frac{R^{2} \omega_{E} M}{\tau \cdot F D R^{2}} \cdot\left(\frac{1}{\left(G R_{3}\right)^{2}}-\frac{1}{\left(G R_{2}\right)\left(G R_{3}\right)}\right)\right]+\left[\frac{R^{2} \omega_{E} M}{\tau \cdot F D R^{2}} \cdot\left(\frac{1}{\left(G R_{4}\right)^{2}}-\frac{1}{\left(G R_{3}\right)\left(G R_{4}\right)}\right)\right]
\end{aligned}
$$




$$
\begin{aligned}
\therefore t_{t}=\frac{R^{2} \omega_{E} M}{\tau \cdot F D R^{2}} & {\left[\frac{1}{\left(G R_{1}\right)^{2}}+\frac{1}{\left(G R_{2}\right)^{2}}-\frac{1}{\left(G R_{1}\right)\left(G R_{2}\right)}+\frac{1}{\left(G R_{3}\right)^{2}}-\frac{1}{\left(G R_{2}\right)\left(G R_{3}\right)}+\frac{1}{\left(G R_{4}\right)^{2}}\right.} \\
& \left.-\frac{1}{\left(G R_{3}\right)\left(G R_{4}\right)}\right]
\end{aligned}
$$

$$
\begin{aligned}
\frac{\partial t_{t}}{\partial G R_{1}} & =\frac{R^{2} \omega_{E} M}{\tau \cdot F D R^{2}}\left[-\frac{2}{\left(G R_{1}\right)^{3}}+\frac{1}{\left(G R_{1}\right)^{2}\left(G R_{2}\right)}\right] \\
\frac{\partial t_{t}}{\partial G R_{2}} & =\frac{R^{2} \omega_{E} M}{\tau \cdot F D R^{2}}\left[-\frac{2}{\left(G R_{2}\right)^{3}}+\frac{1}{\left(G R_{1}\right)\left(G R_{2}\right)^{2}}+\frac{1}{\left(G R_{2}\right)^{2}\left(G R_{3}\right)}\right] \\
\frac{\partial t_{t}}{\partial G R_{3}} & =\frac{R^{2} \omega_{E} M}{\tau \cdot F D R^{2}}\left[-\frac{2}{\left(G R_{3}\right)^{3}}+\frac{1}{\left(G R_{2}\right)\left(G R_{3}\right)^{2}}+\frac{1}{\left(G R_{3}\right)^{2}\left(G R_{4}\right)}\right]
\end{aligned}
$$

Set each equation [(1), (2), (3)] = 0 and solve by method of Substitution.

$$
\text { From (1): } \frac{R^{2} \omega_{E} M}{\tau \cdot F D R^{2}}\left[-\frac{2}{\left(G R_{1}\right)^{3}}+\frac{1}{\left(G R_{1}\right)^{2}\left(G R_{2}\right)}\right]=0
$$

Divide throughout by $\frac{R^{2} \omega_{E} M}{\tau \cdot F D R^{2}}$ and multiply both sides by $\left(G R_{1}\right)^{3}\left(G R_{2}\right)$ :

$$
\begin{gathered}
-2\left(G R_{2}\right)+G R_{1}=0 \\
\therefore G R_{1}=2\left(G R_{2}\right)
\end{gathered}
$$

From (2): $\frac{R^{2} \omega_{E} M}{\tau \cdot F D R^{2}}\left[-\frac{2}{\left(G R_{2}\right)^{3}}+\frac{1}{\left(G R_{1}\right)\left(G R_{2}\right)^{2}}+\frac{1}{\left(G R_{2}\right)^{2}\left(G R_{3}\right)}\right]=0$

Divide throughout by $\frac{R^{2} \omega_{E} M}{\tau \cdot F D R^{2}}$ and multiply both sides by $\left(G R_{1}\right)\left(G R_{2}\right)^{3}\left(G R_{3}\right)$ :

$$
\begin{gathered}
-2\left(G R_{1}\right)\left(G R_{3}\right)+\left(G R_{2}\right)\left(G R_{3}\right)+\left(G R_{1}\right)\left(G R_{2}\right)=0 \\
\text { Sub. } G R_{1}=2\left(G R_{2}\right) \\
-2\left(2 G R_{2}\right)\left(G R_{3}\right)+\left(G R_{2}\right)\left(G R_{3}\right)+\left(2 G R_{2}\right)\left(G R_{2}\right)=0
\end{gathered}
$$




$$
\therefore G R_{3}=\frac{2}{3}\left(G R_{2}\right)
$$

$$
\text { From (3): } \frac{R^{2} \omega_{E} M}{\tau \cdot F D R^{2}}\left[-\frac{2}{\left(G R_{3}\right)^{3}}+\frac{1}{\left(G R_{2}\right)\left(G R_{3}\right)^{2}}+\frac{1}{\left(G R_{3}\right)^{2}\left(G R_{4}\right)}\right]=0
$$

Divide throughout by $\frac{R^{2} \omega_{E} M}{\tau \cdot F D R^{2}}$ and multiply both sides by $\left(G R_{2}\right)\left(G R_{3}\right)^{3}$ :

$$
\begin{gathered}
-2\left(G R_{2}\right)+\left(G R_{3}\right)+\left(G R_{2}\right)\left(G R_{3}\right) \frac{1}{G R_{4}}=0 \\
\text { Sub. GR } R_{3}=\frac{2}{3}\left(G R_{2}\right) \\
-2\left(G R_{2}\right)+\left(\frac{2}{3}\left(G R_{2}\right)\right)+\left(G R_{2}\right)\left(\frac{2}{3}\left(G R_{2}\right)\right) \frac{1}{G R_{4}}=0
\end{gathered}
$$

Multiply both sides by 3 and divide throughout by 2:

$$
-3\left(G R_{2}\right)+G R_{2}+\left(G R_{2}\right)^{2} \frac{1}{G R_{4}}=0
$$

Multiply throughout by $G_{4}$ :

$$
\left(G R_{2}\right)^{2}-2\left(G R_{2}\right)\left(G R_{4}\right)=0
$$

$$
\therefore G R_{2} \neq 0 \text { and } G R_{2}=2 G R_{4}
$$

(c)

$$
v_{1}=\frac{(0.25 \mathrm{~m})(261.799 \mathrm{rad} / \mathrm{s})}{(2.908 \mathrm{rad})(3.0)}=7.502 \mathrm{~m} / \mathrm{s}
$$




$$
\begin{aligned}
& v_{2}=\frac{(0.25 \mathrm{~m})(261.799 \mathrm{rad} / \mathrm{s})}{(1.454 \mathrm{rad})(3.0)}=15.00 \mathrm{~m} / \mathrm{s} \\
& v_{3}=\frac{(0.25 \mathrm{~m})(261.799 \mathrm{rad} / \mathrm{s})}{(0.969 \mathrm{rad})(3.0)}=22.51 \mathrm{~m} / \mathrm{s} \\
& t_{1}=\frac{(0.25 \mathrm{~m})^{2}(261.799 \mathrm{rad} / \mathrm{s})(600 \mathrm{~kg})}{(240 \mathrm{Nm})(3.0)^{2}} \cdot \frac{1}{(2.908 \mathrm{rad})^{2}}=0.537 \mathrm{~s} \\
& t_{2}=\frac{(0.25 \mathrm{~m})^{2}(261.799 \mathrm{rad} / \mathrm{s})(600 \mathrm{~kg})}{(240 \mathrm{Nm})(3.0)^{2}} \cdot\left(\frac{1}{(1.454 \mathrm{rad})^{2}}-\frac{1}{(2.908 \mathrm{rad})(1.454 \mathrm{rad})}\right)=1.075 \mathrm{~s} \\
& t_{3}=\frac{(0.25 \mathrm{~m})^{2}(261.799 \mathrm{rad} / \mathrm{s})(600 \mathrm{~kg})}{(240 \mathrm{Nm})(3.0)^{2}} \cdot\left(\frac{1}{(0.969 \mathrm{rad})^{2}}-\frac{1}{(1.454 \mathrm{rad})(0.969 \mathrm{rad})}\right)=1.615 \mathrm{~s} \\
& t_{4}=\frac{(0.25 \mathrm{~m})^{2}(261.799 \mathrm{rad} / \mathrm{s})(600 \mathrm{~kg})}{(240 \mathrm{Nm})(3.0)^{2}} \cdot\left(\frac{1}{(0.727 \mathrm{rad})^{2}}-\frac{1}{(0.969 \mathrm{rad})(0.727 \mathrm{rad})}\right)=2.148 \mathrm{~s} \\
& t_{t}=t_{1}+t_{2}+t_{3}+t_{4}=0.537 s+1.075 s+1.615 s+2.148 s=5.375 s \\
& \text { Surface Plot of Total Time(GR1,GR2) when } \\
& \mathrm{GR}_{3}=1
\end{aligned}
$$

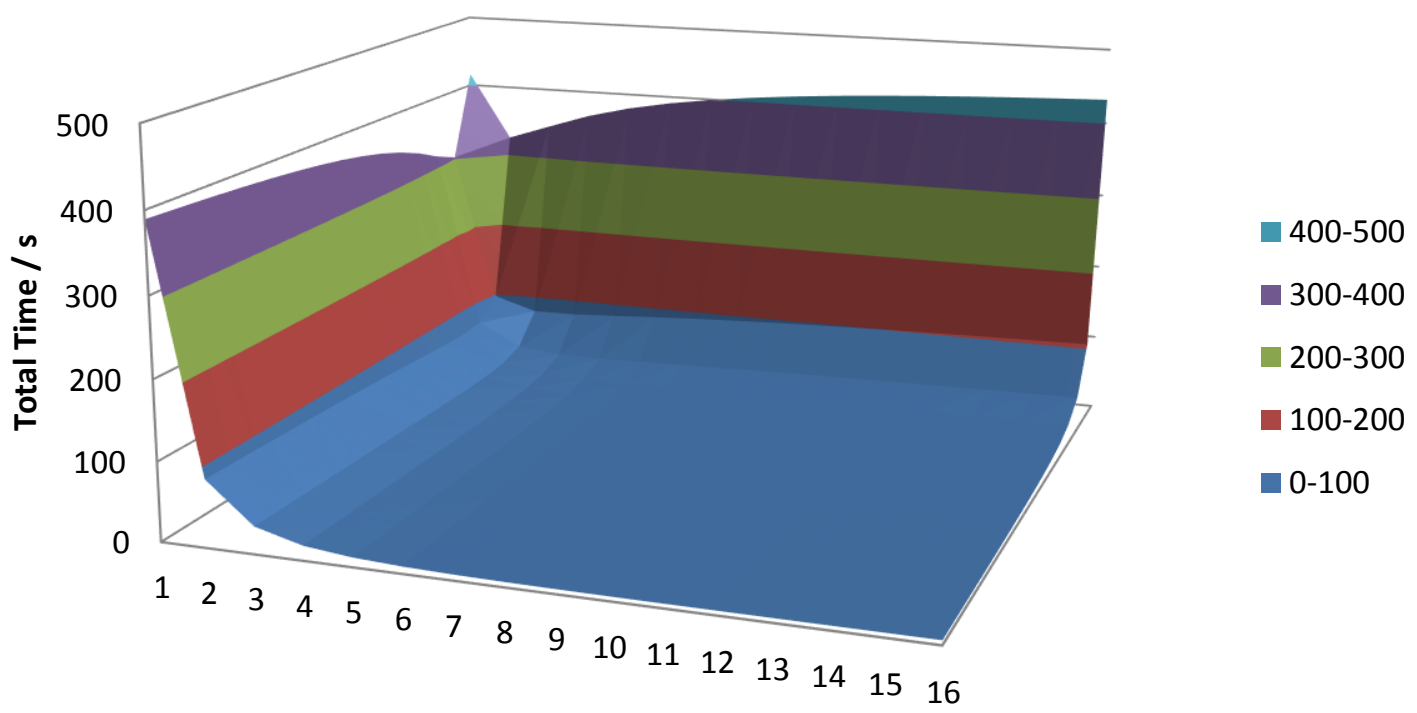

Figure 1: Shown is a surface plot for the total time of gear ratios 1 and 2 when gear ratio 3 is equal to 1 . 